\title{
A comparison between D2-40 and c-KIT immunohistochemistry for the human fetal testis and ovary at the second trimester of gestation
}

\author{
By
Zhe Wu JIN ${ }^{1}$, Young Gon KIM ${ }^{2}$, Hee Chul YU ${ }^{1}$, Gen MURAKAMI ${ }^{3}$, Mineko FUJIMIYA ${ }^{4}$ and Baik Hwan $\mathrm{CHO}^{1}$
${ }^{1}$ Department of Surgery and Research Institute of Clinical Medicine, Chonbuk National University Medical School, Jeonju, Korea
${ }^{2}$ Department of Urology, Chonbuk National University Medical School, Jeonju, Korea
${ }^{3}$ Division of Internal Medicine, Iwamizawa Koujin-kai Hospital, Iwamizawa, Japan
${ }^{4}$ Department of Anatomy, Sapporo Medical University School of Medicine, Sapporo, Japan

-Received for Publication, November 12, 2009-

Key Words: M2A, c-KIT, testis, ovary, human fetus

\begin{abstract}
Summary: Both M2A (D2-40) and c-KIT have frequently been used as markers of germ cell tumors. However, comparative studies of their immunoreactivities in human fetal gonads have been limited. Using horizontal semiserial whole-abdomen sections of 9 human abortuses at 12 weeks ( 2 males and 1 females; CRL 70-80 mm), 15 weeks ( 2 males and 3 females; $115-125 \mathrm{~mm}$ ) and 18 weeks ( $1 \mathrm{female} ; 155 \mathrm{~mm}$ ) of gestation, we identified germ cells in the testis and ovary on the basis of c-KIT immunoreactivity. M2A was also stained using near or adjacent sections. In 12-week fetuses, c-KIT immunoreactivity was weak, but M2A immunoreactivity was consistently strong. At 15 and 18 weeks of gestation, c-KIT immunoreactivity was found in most germ cells. M2A was expressed in Sertoli cells as well as in germ cells, but was not expressed in ovarian follicles undergoing meiosis. M2A appears to be a more useful marker of germ cells than c-KIT in human fetal testis and ovary at the second trimester. M2A is also reactive in fetal Sertoli cells, but its expression is consistently weaker than in germ cells.
\end{abstract}

\section{Introduction}

M2A (D2-40), a glycosylated monomeric sialoglycoprotein, is a well-known marker of mesothelioma and lymphatic vessels, and also a marker of human fetal gonocytes ${ }^{1)}$ and immature Sertoli cells ${ }^{2}$. In contrast, c-KIT is a receptor tyrosine kinase that is a wellrecognized marker of pluripotent cells, which began to be applied for identification of human fetal germ cells ${ }^{3,4)}$ somewhat later than M2A. Robinson et al. ${ }^{5)}$ reported that in 13-21-week fetuses of both sexes, c-KIT was localized in the cell membrane, except for oocytes within primordial follicles, where it was localized to the cytoplasm.

Gaskell et al. ${ }^{6}$, in a study of male fetuses at 7-19 weeks of gestation, found that fetal germ cells were composed of a heterogeneous population comprising gonocytes (c-KIT positive), intermediate germ cells and prespermatogonia (C-KIT negative). Such heterogeneity has also been reported in the fetal ovary, based on immunohistochemistry for several markers including c-KIT, but not $\mathrm{M} 2 \mathrm{~A}^{7)}$. Pauls et al. $^{8)}$ reported co-expression of c-KIT and M2A in fetal oogonia. Likewise, according to Pauls et al. ${ }^{9)}$, nearly all male germ cells with the morphological features of gonocytes and intermediate cells coexpressed c-KIT and M2A: starting from week 12 of gestation, their number increased up to week 18/19 and then declined continuously during further development until, after week 25, prespermatogonia were predominant and did not express these markers, possibly because their pluripotency had been lost. Similar findings were reported by O'Shaughnessy et al. ${ }^{10}$ on the basis of observations of 11-19-week male fetuses, although they did not use M2A as a marker. In spite of the frequent application of M2A or c-KIT for fetal studies, there have been few attempts to compare the two markers ${ }^{8,9)}$ (for details see Discussion). Consequently, the aim of the present study was to re-examine the immunohistochemistry of M2A (D2-40) and c-KIT using fetuses at 12-18 weeks of gestation, a stage at which fetal germ cells increase in number. 


\section{Materials and Methods}

In accordance with the provisions of the Declaration of Helsinki, 1995 (as revised in Edinburgh 2000), we examined 9 human abortuses at 12 -weeks of gestation ( 2 males and 1 females; CRL 70-80 mm), 15-weeks (2 males and 3 females; 115-125 mm) and 18-weeks (1 female; $155 \mathrm{~mm}$ ). With the agreement of the families concerned, these fetuses had been donated to department of Anatomy, Chonbuk National University in Korea, and use of the fetuses for research had been approved by the university ethics committee. All specimens were normal according to the surface observations. The specimens had been fixed in neutral $10 \%$ formalin solution, decalcified using EDTA, and paraffin-embedded for histological examination. Many triple sets of serial horizontal paraffin sections ( $5 \mu \mathrm{m}$ thick) were prepared at 100 microm interval for the abdomen including the testis or ovary. Hematoxylin and eosin (HE) staining was performed for one of the three sections, while other 2 sections were used for immunohistochemistry. The primary antibodies used are 1) rabbit anti-human c-KIT monoclonal antibody (Dako, Glostrup, Denmark) and 2) rabbit anti-human M2A monoclonal antibody (Nichirei D2-40, Tokyo, Japan). The second antibody was labeled with horseradish peroxidase (HRP) and antigen-antibody reactions were detected according to the HRP-catalysed reaction with diaminobenzidine. Counter-staining with hematoxylin was performed.

\section{Results}

Although we prepared many triple sets of serial sections stained for HE, c-KIT and M2A, the present figures were not prepared using adjacent sections because, at the beginning of this study, the results of immunohistochemistry was often unstable. In 12-week fetuses, c-KIT immunoreactivity was weak in germ cells, whereas M2A (D2-40) immunoreactivity was consistently strong (Fig. 1). In the testis, M2A-positive germ cells in each tubule outnumbered c-KIT-positive cells almost threefold. Reactivities for both markers were positive in the cell membranes, and a proportion of Sertoli cells were weakly positive for M2A.

At 15 and 18 weeks of gestation, c-KIT immunoreactivity was evident in most germ cells. M2A was expressed in Sertoli cells as well as in germ cells (Fig. 2 ), but was not expressed in ovarian follicles undergoing meiosis (Fig. 3). In the testis, the number of M2Apositive germ cells per tubule was almost the same as that of c-KIT-positive cells. Because M2A reactivity was strong in Sertoli cells, lower-magnification views often demonstrated entire tubules as positive areas in the testis (Fig. 2B). Both antigens showed stronger expression in the fetal oogonia along the surface of the ovary than in
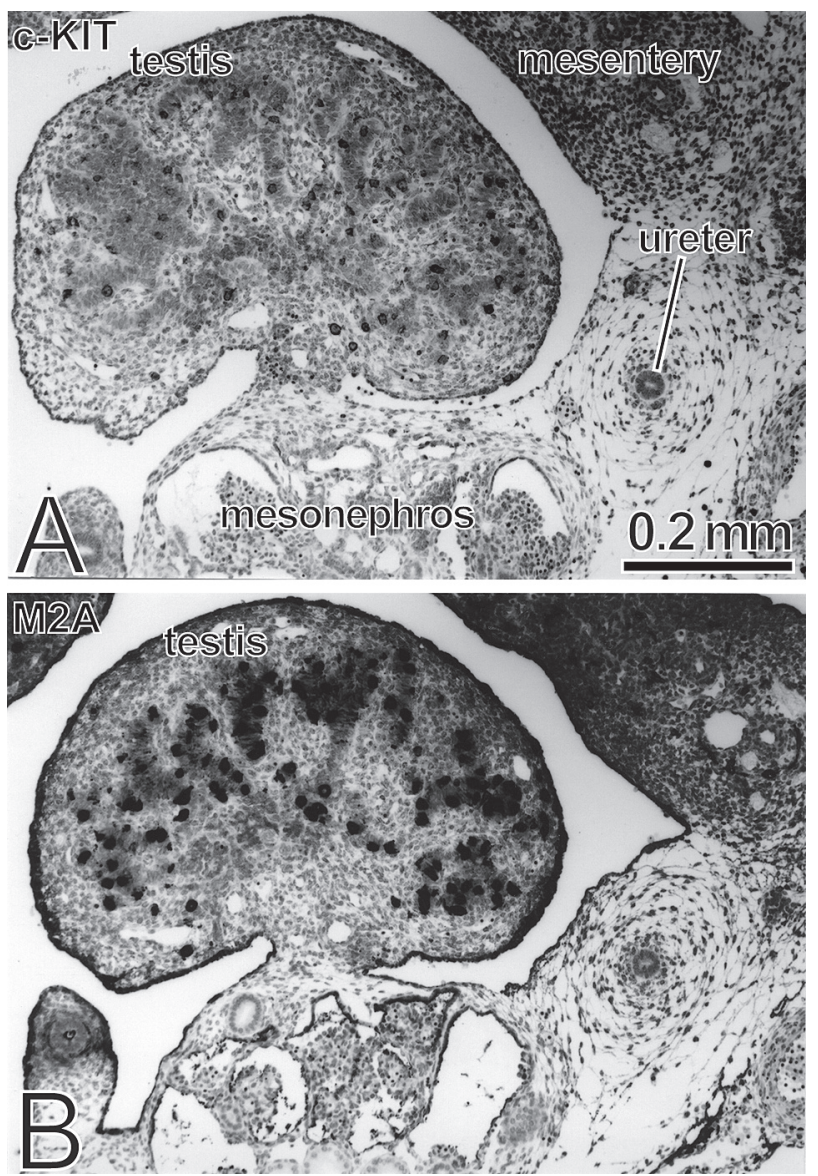

Fig. 1. Immunohistochemistry of the testis of a 12-week-fetus. Panel A (c-KIT immunohistochemistry) and Panel B (M2A or D2-40 immunohistochemistry) are prepared at the same magnification and display near transverse sections. M2A-positive cells appeared to be greater in number than c-KIT-positive cells. In all figures including Fig. 1, the upper side of each panel corresponds to the ventral side of the specimen.

the center (Fig. 3). However, a larger number of centrally located cells were positive for c-KIT than for M2A. Immunoreactivity for c-KIT or M2A was localized to the cell membrane except for c-KIT reactivity in oocytes within primordial follicles, where it was localized to the cytoplasm. The germ/Sertoli cell ratio was estimated to be 1:3-4 when counted in M2A-stained sections.

In addition, other than in gonads, M2A expression was found in lymphatic vessels, dorsal root ganglia, peripheral nerves including sympathetic nerve ganglia, developing cartilage, and the mucosal layer of the urinary bladder, while c-KIT was also expressed in peripheral nerves and intestine.

Consequently, it appeared that M2A was expressed earlier and more strongly than c-KIT in human fetal testis and ovary in spite of variations in fetal tissue preservation, although it was also reactive in Sertoli cells at 15- 

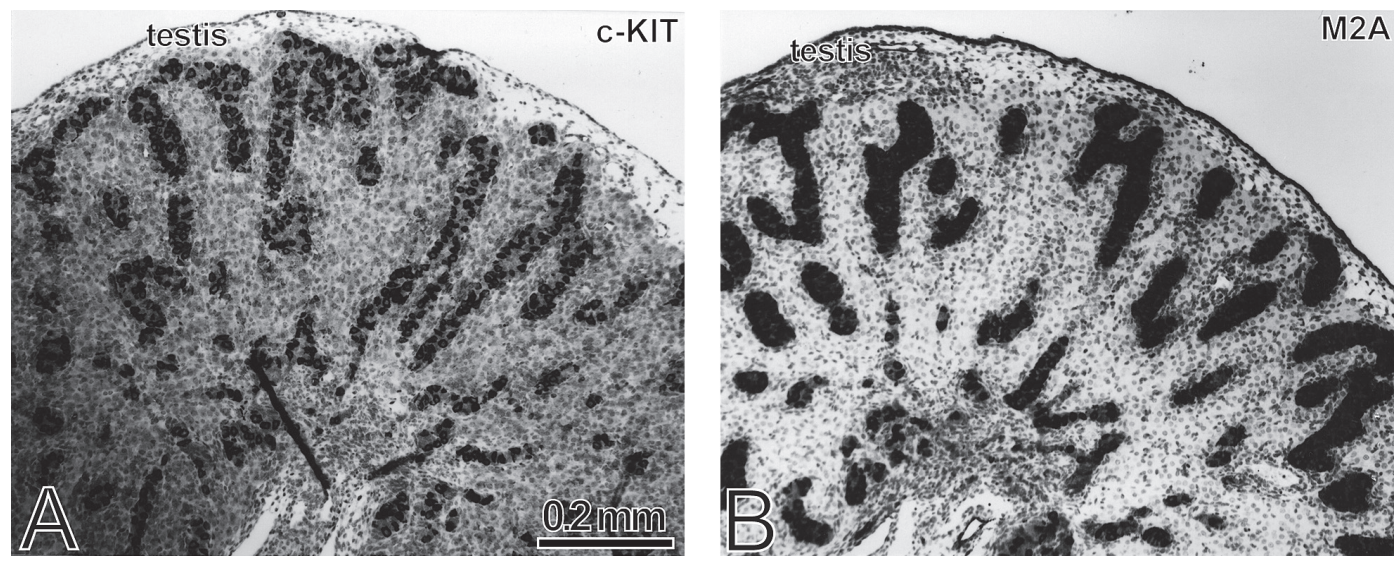

Fig. 2. Immunohistochemistry of the testis of a 15 -week-fetus.

Panel A (c-KIT immunohistochemistry) and Panel B (M2A or D2-40 immunohistochemistry) are prepared at the same magnification and display near transverse sections. M2A reactivity is so strong that both of germ cells and Sertoli cells make dark-colored cord-like structures.
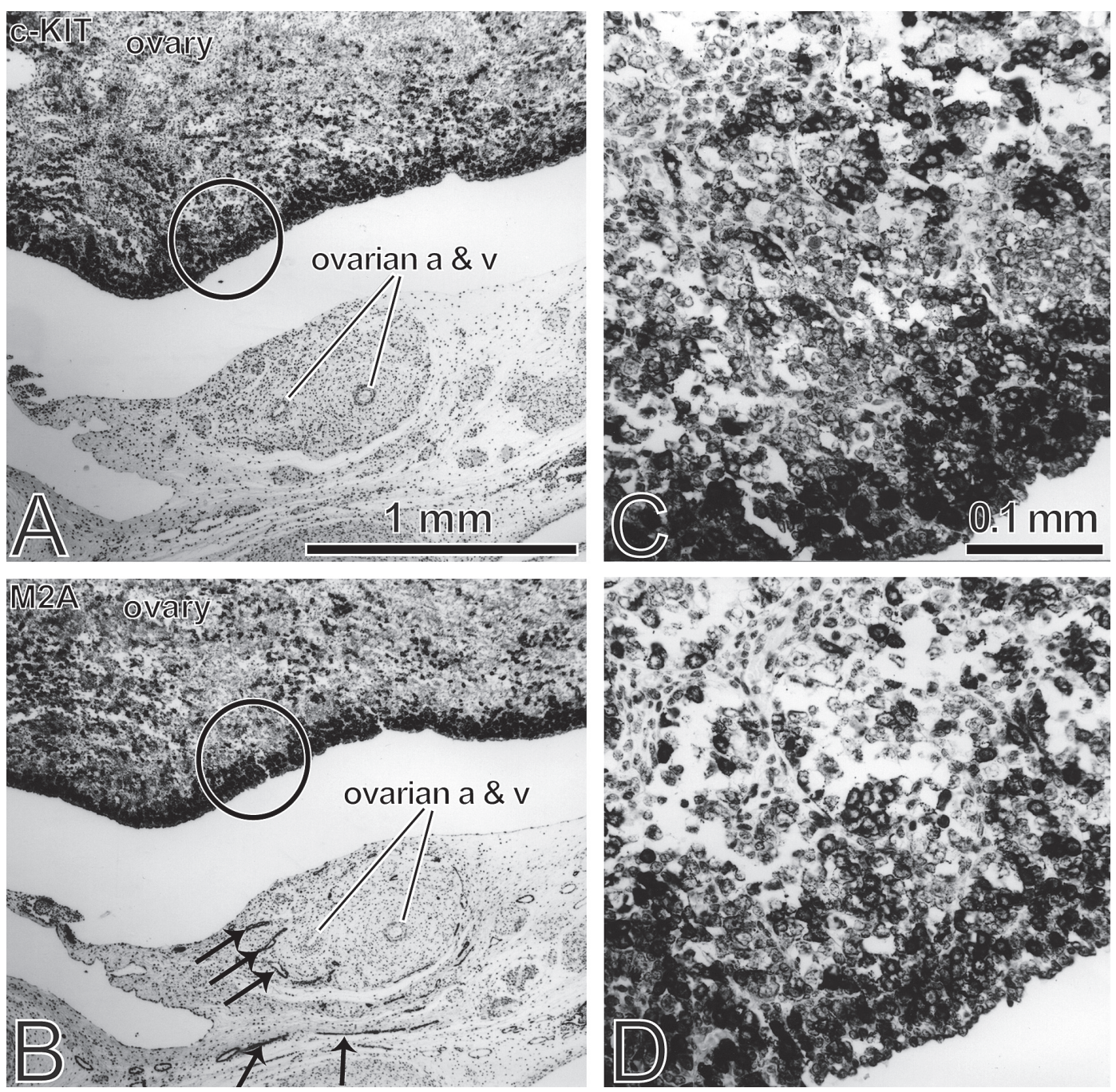

Fig. 3. Immunohistochemistry of the ovary of an 18-week-fetus.

Panel A (c-KIT immunohistochemistry) and Panel B (M2A or D2-40 immunohistochemistry) are prepared at the same magnification and display near transverse sections. Panels $\mathrm{C}$ and $\mathrm{D}$ are higher magnification views of a circle in panel A or B, respectively. More numbers of centrally located cells express c-KIT than M2A or D2-40. M2A reactivity is found in lymphatic vessels around the ovarian artery and vein (ovarian a\&v). 
18 weeks of gestation.

\section{Discussion}

In their detailed study of human fetal testis, Pauls et $a l .{ }^{9)}$ described that the proportions of c-KIT- and M2Aimmunoreactive cells among total germ cells, identified according to their large size and round nuclei, were both $88 \%$ at week $18 / 19$, corresponding to the peak of maximal expression during gestation. They also reported that the germ/Sertoli cell ratio was 1:5-6.5 at 12-19 weeks. However, in the present series of specimens, the ratio was estimated to be 1:3-4 when counted in M2A-stained sections at the corresponding stages. The latter authors noted the extreme robustness of $\mathrm{M} 2 \mathrm{~A}$ expression, possibly due to fixation artifacts, but they did not report M2A expression in Sertoli cells. Although such expression has been reported elsewhere ${ }^{2,11)}$, the strong M2A expression by Sertoli cells appeared to be less known than our expectation.

Franke et al. $^{12)}$ reported that cytokeratin 18 was a marker of fetal Sertoli cells, although they also tested M2A. Bar-Shira Maymon et al. ${ }^{13)}$ compared the M2A immunoreactivity of Sertoli cells in a 31-year-old azoospermic man with testicular damage after cancer cytotoxic chemotherapy with that in a 4-year-old male as a "control". Their findings demonstrated that the morphology of the M2A-positive area was similar to that observed in the present study at lower magnification. Pauls et al. ${ }^{9)}$ and Sonne et al. ${ }^{11)}$, using normal specimens, reported that M2A-positive germ cells were drastically decreased in number at the third trimester of gestation, in contrast to increased expression of melanoma-associated antigen, MAGE-A4. However, changes in the expression of M2A in fetal Sertoli cells were not well described. With regard to tissues other than the testis, there is no information as to whether M2A is expressed in stromal cells of the fetal ovary. Our present study showed that M2A-positive cells were less numerous than c-KIT-positive cells in the central area of the fetal ovary.

Consequently, M2A seems to be more useful as a marker of germ cells than c-KIT in human fetal testis and ovary at the second trimester. M2A is also expressed in fetal Sertoli cells, but at a consistently weaker level than in germ cells.

\section{Acknowledgements}

This study was supported by a grant (0620220-1) from the National R \& D Program for Cancer Control, Ministry of Health \& Welfare, Republic of Korea.

\section{References}

1) Jørgensen N, Giwercman A, Müller J and Skakkeback NE. Immunohistochemical markers of carcinoma in situ of the testis also expressed in normal infantile germ cells. Histopahthology 1993; 22:373-378.

2) Baumal R, Bailey D, Giwercman A, Skakkeback N, Stratis M and Marks A. A novel maturation marker for human Sertoli cells. Int J Andorol 1989; 12:354-359.

3) Horie K, Fujita J, Takakura K, Kanzaki H, Suginami H, Iwai M, Nakayama $\mathrm{H}$ and Mori T. The expression of c-kit protein in human adult and fetal tissues. Hum Reprod 1993; 8:1955-1962.

4) Jørgensen N, Rajpert-De Meyts E, Graem N, Müller J, Giwercman A and Skakkeback NE. Expression of immunohistochemical markers for testicular carcinoma in situ by normal human fetal germ cells. Lab Invest 1995; 72:223-231.

5) Robinson LL, Gaskell TL, Saunders PT and Anderson RA. Germ cell specific expression of c-kit in the human fetal gonad. Mol Hum Reprod 2001; 7:845-852.

6) Gaskell TL, Esnal A, Robinson LL, Anderson RA and Saunders PT. Immunohistochemical profiling of germ cells within the human fetal testis: identification of three subpopulations. Biol Reprod 2004; 71:2012-2021.

7) Kerr CL, Hill CM, Blumenthal PD and Gearhart JD. Expression of pluripotent stem cell markers in the human fetal ovary. Hum Reprod 2008; 23:589-599.

8) Pauls K, Franke FE, Büttner R and Zhou H. Gonadblastoma: evidence for a stepwise progression to dysgerminoma in a dysgenetic ovary. Virchows Arch 2005; 447:603-609.

9) Pauls K, Schorle H, Jeske W, Brehm R, Steger K, Wernert N, Büttner R and Zhou H. Spatial expression of germ cell markers during maturation of human fetal male gonads: an immunohistochemical study. Hum Reprod 2006; 21:397-404.

10) O’Shaughnessy PJ, Baker PJ, Monteiro A, Cassie S, Bhattacharya $\mathrm{S}$ and Fowler PA. Developmental changes in human testicular cell numbers and messenger ribonucleic acid levels during the second trimester. J Clin Endocrinol Metab 2007; 92:4792-4801.

11) Sonne SB, Herlihy AS, Hoei-Hansen CE, Nielsen JE, Almstrup K, Skakkebaek NE, Marks A, Leffers H and Rajpert-De Meyts E. Identification of M2A (D2-40) antigen and gp36 (Aggrus, T1A-2, podoplanin) in human developing testis, testicular carcinoma in situ and germ-cell tumors. Virchows Arch 2006; 449:200-206.

12) Franke FE, Pauls K, Rey R, Marks A, Bergmann M and Steger K. Differentiation markers of Sertoli cells and germ cells in fetal and early postnatal human testis. Anat Embryol 2004; 209:169-177.

13) Bar-Shira Maymon B, Yogev L, Marks A, Hauser R, Botchan A and Yavetz H. Sertoli cell inactivation by cytotoxic damage to the human testis after cancer chemotherapy. Fertil Steril 2004; 81: 1391-1394 